Scheinbare Oerter der Sterne.

Diese wurden einfach (als mittlere Oerter) den Catalogen entnommen, auf 1878.0 und auf den seheinbaren Ort reducirt. Alle sonstigen Correctionen uberlasse ich den Rechnern.
$a=1^{\mathrm{b}} 24^{\mathrm{m}} 5^{\mathrm{s} 900}-7^{0} 3^{\prime} 54^{\prime} 98$
$\beta=15.26 .37 .026$
$-7.40 .21 .24$
$\gamma=15.29 \cdot 18.732$
$-8.34 \quad 9.93$
B. Weisse 418 .
463. Lal. 28361. Lal. nicht benutzt.
512. 28385.

Ich fand $\gamma=7 \mathrm{~m} 8$ viel heller als ihn Bessel und Lalande, nämlich 9m, angeben.

Es ist möglich, den Cometen noch weiter zu verfolgen.

Athen 1878 Aug. 15.

J. F. Julius Schmidt.

\title{
Beobachtungen von Sonnenflecken.
}

\section{(Fortsetzung zu Nr. 2180.)}

Periode 230 of 1878 Jan. 3 bis 29.

Nr. $1 \quad L=2 \overline{0} 3^{\circ} ; \quad b=-1 \overline{0}^{\circ} 6$,

kleiner Fleck, $(\mathrm{n}=1)$; beob. Jan. 7 .

Keine Flecke wurden beobachtet Jan. 8 bis 18 .

Nr. $2 \quad \mathrm{~L}=95 \quad \mathrm{~b}=+\dot{s .0}$

(n=2) kleine Flecke, beob. Jan. 24 und 26;

darauf keine Flecke beob. Jan. 28 und 30.

Periode 231 of 187 is Jan. 30 bis Febr. 25.

$$
\begin{array}{llll}
\text { Nr. } 3 & \mathrm{~L}=280 & \mathrm{~b}=-5.3 & (\mathrm{n}=3) \\
\text { Nr. } 4 & \mathrm{~L}=262 & \mathrm{~b}=-6.5 & (\mathrm{n}=3)
\end{array}
$$

Diese aneinander gereiheten Gruppen llabe ich nur zwischen Wolkenlücken gesehen, aber ohne die Fleckenörter messen zu können. Durch gütige Mittheilung des Herru Dr. v. Konkoly erhielt ich die auf seiner Sternwarte gemessenen Oerter, welche zu den obigen Angaben zusammengefasst sind.

Keine Flecke beob. Febr. 12, 13, 16, 18, 25.

Periode 232 of 1878 Febr. 26 bis März 24.

Keine Flecke beob. Febr. 26 bis März 2.

Nr. $\bar{L} \quad \mathrm{~L}=285 \quad \mathrm{~b}=+4.3$

(n $=2$ ) Gruppen kleiner Flecke, beob. März 3.

Keine Flecke beob. Marz 7.

Nr. $\& \quad \mathrm{~L}=214 \quad \mathrm{~b}=0.0$

(n=1) kleiner Fleck, beob. März 9 .

Keine Flecke beob. März 10.

Nr. $7 \quad L=150 \quad b=+8.0$

(n $=6$, Gruppe, beob. März 13 bis 17 .

Keine Flecke beob. März 19, 20, 22, 24.

Periode $233 \sigma 1878$ Marz 25 bis April 20.

Während der ganzen Periode kamen keine Flecke vor.

Periode 234 o 1878 April 21 bis Mai 17.

Auch während dieser Periode kamen keine Flecke ror. Wir zählen aber (wie früher zur Vereinigung von $4 \frac{1}{2}$ Perioden nur die erste Halfte der Periode und setzen zur Herleitung der mittleren heliographischen Breite den für $b=0.0$ beobachteten Fleck bei jeder der beiden Halbkugeln mit $1 / 2$ an, wobei zufällig für beide Halbkugeln dieselbe mittlere Breite erhalten wird. Bei den Häufigkeitszahlen wollen wir jenen Fleck zur Vermeidung eines Bruches, und weil er nur klein war, nicht mitzählen.

Aus der Vergleiclıung mit den Zahlen für das letzte Drittel des Jahres 1877 (Astr. Nachr. 2180 pag. 314) ersieht man, dass die Häufigkeitszahlen noch weiter abgenommen haben, und dass die mittlere heliographische Breite der Flecke sehr beträchtlich abgenommen liat.

Für das erste Drittel des Jahres gilt:

nördl. Halbkugel

sïdl. Halbkugel

10
7 $\quad \begin{gathered}6^{0} 9 \\ 6.9\end{gathered}$

Wälırend das Fleckenminimum noch tortdauert, ist kürzlich eine sehr auffällige Steigerung der Protuberanzen eingetreten. Es sind namentlich an den Tagren. Juli 22 $24,25,31$ Aug. 1 und 9 ausgezeichnete Protuberanzen beobaclitet.

Bemerkung. Beim Merkurdurchgang am 6. Mai habe ich den Eintritt spectroscopisch beobachtet. Die Schilderung dieser Beobachtung findet man in den Monatsberichten der Berliner Akad. d. W. vom 9. Mai 1878 pag. 359 und 360 .

Potsdam 1878 August 10. 